\title{
Experimental results of elevation change analysis in the Antarctic ice sheet using DEMs from ERS and ICESat data
}

\author{
Zhenxiong GU, ${ }^{1,2}$ Tiantian FENG, ${ }^{1,2}$ Marco SCAIONI, ${ }^{1,2}$ Hangbin WU, ${ }^{1,2}$ Jun LIU, ${ }^{1,2}$ \\ Xiaohua TONG, ${ }^{1,2}$ Rongxing $\mathrm{LI}^{1,3}$
${ }^{1}$ Center for Spatial Information Science and Sustainable Development Applications, Tongji University, Shanghai, China E-mail: fengtiantian@tongji.edu.cn
${ }^{2}$ College of Survey and Geo-Informatics, Tongji University, Shanghai, China
${ }^{3}$ Mapping and GIS Lab, Department of Civil, Environmental and Geodetic Engineering, The Ohio State University, \\ Columbus, $\mathrm{OH}, \mathrm{USA}$
}

\begin{abstract}
The aim of this research is to investigate elevation changes in the Antarctic ice sheet by comparing two digital elevation models (DEMs) derived from satellite altimetry data covering the period 1994-2004. Data collected by ERS-1/2 satellite radar altimetry and by NASA GLAS/ICESat laser altimetry were used. After preprocessing and resampling at the same spatial resolution, both DEMs were compared in a pointwise fashion and elevation differences computed, which consisted of three main components: (1) actual elevation change, (2) errors in the original data sources and (3) interpolation errors that arose during generation of the DEMs. The objectives of the research were to analyze errors, attempt to mitigate systematic effects when possible, and draw some conclusions about the limitations of using DEM products for computing ice-sheet elevation change at local and continental scales. A linear correlation between errors in elevation differences and surface slope was found in the slope range $\left[0^{\circ}, \mathbf{0 . 4}^{\circ}\right]$. This trend was interpreted as residual slope-induced systematic error and compensated for. Finally, an elevation difference map of the Antarctic ice sheet was generated. Analysis of the derived elevation changes at the drainage basin was also made. Results are compared with the results of previous studies.
\end{abstract}

KEYWORDS: ground ice, ice-sheet mass balance, surface melt

\section{INTRODUCTION}

Elevation changes to the polar ice sheets are highly sensitive indicators of global climate change. Consequently, many efforts have been made to monitor the evolution of polar areas, especially in Antarctica and Greenland. Currently there are three main ways to estimate the ice-sheet mass balance (Rignot and Thomas, 2002): (1) the mass budget method, (2) measurements of elevation change over time by satellite altimetry and (3) weighing of the ice sheets by gravity measurements.

This paper presents an analysis of the evaluation of Antarctic surface elevation changes using two digital elevation model (DEM) products derived from European Remote-sensing Satellite (ERS) radar altimetry (RA) data and GLAS/ICESat satellite laser altimetry (LA) data collected over the past two decades. During the geodetic phase of the ERS1 satellite of the European Space Agency (ESA), large amounts of RA data were gathered over Antarctica from 1994 to 1995. The NASA ICESat (Ice, Cloud and land Elevation Satellite) mission from 2003 to 2009 collected data on ice surface elevation using the Geoscience Laser Altimeter System (GLAS) carried on board. Data are also available from the latest ESA CryoSat-2 mission, which began gathering data in April 2010. CryoSat-2 is dedicated to precise monitoring of changes in the polar sea ice and ice sheets (Wingham and others, 2006a).

Satellite RA data acquired by ERS- 1 and -2 have been exploited widely to assess elevation changes in the Antarctic ice sheet. An elevation change rate of $63 \%$ of the grounded Antarctic ice sheet over a 5 year period (1992-96) was estimated using $4 \times 10^{6}$ ice-mode range records at crossing points of the satellites' orbit ground tracks (Wingham and others, 1998). Antarctic ice-sheet elevation change over a 6 year period (1995-2000) was analyzed using $123 \times 10^{6}$ elevation change measurements from ERS-2 ice-mode satellite RA data covering an area of $\sim 7.2 \times 10^{6} \mathrm{~km}^{2}$ (Davis and Ferguson, 2004). Elevation change over a 12 year period (1992-2003) covering $8.5 \times 10^{6} \mathrm{~km}^{2}$ of the grounded Antarctic ice-sheet interior ( $\sim 70 \%$ of the total ice-sheet area) was measured by Davis and others (2005) and Wingham and others (2006b).

As the intrinsic limitation of the ERS altimetry system, RA data tend to have relatively poor coverage and accuracy near the ice-sheet margins and in other areas of steep relief (Bamber and others, 2009). Great improvements (especially spatial coverage near the coasts and regions of steep topography) have been made for the more recent ICESat and CryoSat-2 observations, which focus more on change detection in the polar environment. Comparison between Gravity Recovery and Climate Experiment (GRACE) gravimetric data and ICESat laser data from 2003 to 2007 over Antarctica was carried out by Gunter and others (2009) and showed strong spatial correlations between these two independent datasets. The mass balance of polar ice sheets was carefully estimated by combining an ensemble of satellite altimetry, interferometry and gravimetry datasets (Shepherd and others, 2012). These results, which have been obtained by and discussed among a group of more than 40 researchers worldwide, are considered the state-of-the-art achievements on Antarctic ice-sheet mass balance for the period 1992-2011. 
Table 1. Some basic spatio-temporal parameters of the satellite missions and DEMs used to estimate Antarctic surface change

ERS (JLB97) DEM

17 Jul 1991 to 3 Oct 2000

Satellite launch/stop date Source data

Altimeter footprint size

Spatial coverage

DEM resolution

Footprint distribution

Along-track

Across-track ic phases 10 Apr 1994 to 21 Mar 1995

2-3 km, square

North of $81.5^{\circ} \mathrm{S}$

$5 \mathrm{~km}$

$335 \mathrm{~m}$

$\sim 4 \mathrm{~km}$ at $60^{\circ} \mathrm{S} ; 2 \mathrm{~km}$ at $70^{\circ} \mathrm{S}$
ICESat DEM

13 Jan 2003 to 11 Oct 2009

The first seven operational periods Feb 2003 to Jun 2005

$52 \mathrm{~m} \times 95 \mathrm{~m}$

North of $86^{\circ} \mathrm{S}$

$500 \mathrm{~m}$

$172 \mathrm{~m}$

$\sim 20 \mathrm{~km}$ at $70^{\circ} \mathrm{S}$
The presented research results are limited to evaluation of the two above-mentioned Antarctic DEM products and their application to elevation change analysis over the entire continent from 1994 to 2004. In particular, two publicly available DEM products created using ERS and ICESat altimetry datasets have been adopted (Bamber, 1994, 2000; DiMarzio and others, 2007). Details on production of the two DEMs are addressed in the next section. Some large errors in the satellite altimetry missions were caused by the different abilities of laser vs radar waves to penetrate the snowpack (Rémy and others, 2012). These differing abilities were difficult to compensate for with an appropriate retracking model (Bamber and others, 2009). In addition, any slope-induced errors should be sufficiently modeled for the purpose of elevation change analysis (Hurkmans and others, 2012). Additional interpolation errors may be introduced by the gridding process, where evenly distributed gridpoints were interpolated from uneven along- and acrosstrack altimetry data. If these errors are not appropriately estimated and corrected, the elevations of the DEMs may not directly represent the actual changes to the ice sheets. Therefore, the initial difference in surface elevation obtained through analysis of the differences between the two DEM products contains two main parts: (1) the actual elevation change that we want to obtain, and (2) the errors existing in the DEM products which may be caused by the abovementioned error sources. Here we assess the quality of these two DEMs and their appropriateness for ice-sheet change evaluation. A linear correction model is established by a regression analysis between terrain slopes and elevation errors. It is then applied to the computed elevation differences. Finally, an elevation difference map of the Antarctic ice sheet from 1994 to 2004 is presented.

\section{DATA AND METHODOLOGY}

The DEMs of the whole of Antarctica used in this research are (Table 1): (1) an ERS DEM entitled JLB97 (Bamber and Gomez-Dans, 2005) that was produced by Bamber (1994, 2000) and validated by Bamber and Bindschadler (1997) and Bamber and Gomez-Dans (2005); and (2) an ICESat DEM produced by DiMarzio and others (2007).

The JLB97 DEM was derived from the interpolation of $\sim 40 \times 10^{6}$ data points north of $81.5^{\circ} \mathrm{S}$, the latitude limit of ERS-1 satellite tracks. Starting in April 1994, the satellite was placed in two long repeat cycles of 168 days each. The two geodetic phases were offset from each other, resulting in an equivalent repeat cycle of 336 days. Bamber (1994) employed the 'relocated method' to correct any slopeinduced error during the production of the JLB97 DEM. In this method, corrected range, slope magnitude and direction are calculated to relocate the satellite position alongtrack. As reported by Bamber and Bindschadler (1997), $\sim 8 \%$ of the area covered did not have valid data. These areas were concentrated in regions of high relief such as the Transantarctic and Prince Charles Mountains, the Antarctic Peninsula and around the Amery Ice Shelf. For these areas the missing altimetry information was replaced using existing maps, whose uncertainty was much worse than the expected accuracy of ERS RA data. The same was done for the region south of the satellite coverage limit, with the aim of having a complete DEM of the entire continent. Moreover, while the slope-induced errors were corrected using slope information less accurate than ICESat data, this dataset also suffers from roughness-dependent surface bias (Bamber and others, 2009).

Bamber and Bindschadler (1997) combined the JLB97 DEM with ice thickness data to qualitatively examine the correspondence between bed topography and surface expression of streaming as they can be seen in Landsat Thematic Mapper (TM) images. They took Ice Streams D and E (Bindschadler and MacAyeal Ice Streams) around the Ross Ice Shelf to demonstrate that the vertical resolution of the JLB97 DEM suffices to identify surface features at sub-meter scale. On the other hand, they did not provide any absolute assessment of the vertical accuracy against benchmarking datasets. Bamber and Gomez-Dans (2005) used the first two campaigns of ICESat/GLAS data (altimetry points along the tracks) to quantitatively examine the JLB97 DEM as a function of surface slope. A linear systematic error was found. Elevation differences are in the range $0.5-1.6 \mathrm{~m}$ between the JLB97 DEM and ICESat data over the central low-slope plateau area of East Antarctica; they exceed $20 \mathrm{~m}$ in the coastal area.

The ICESat DEM used in this research was derived from ICESat/GLAS data as described by DiMarzio and others (2007) in the area north of $86^{\circ} \mathrm{S}$ where LA data were available. While the accuracy of the interpolated surface is reasonable in those areas close to the raw points (decimeter level), the long across-track distances (Table 1) caused a higher level of uncertainty in the intermediate regions between tracks. To overcome this problem (Bamber and others, 2009) both datasets were fused together after proper data filtering according to return-echo waveform shape, backscatter coefficient and retracking correction value. A total of $27 \%$ of the ERS data were filtered out (Bamber and Bindschadler, 1997). Geophysical filters including attitude quality indicator, number of peaks found in the returns, reflectivity, gain value and variance of waveform from Gaussian were used to remove $5.4 \%$ of the ICESat data 


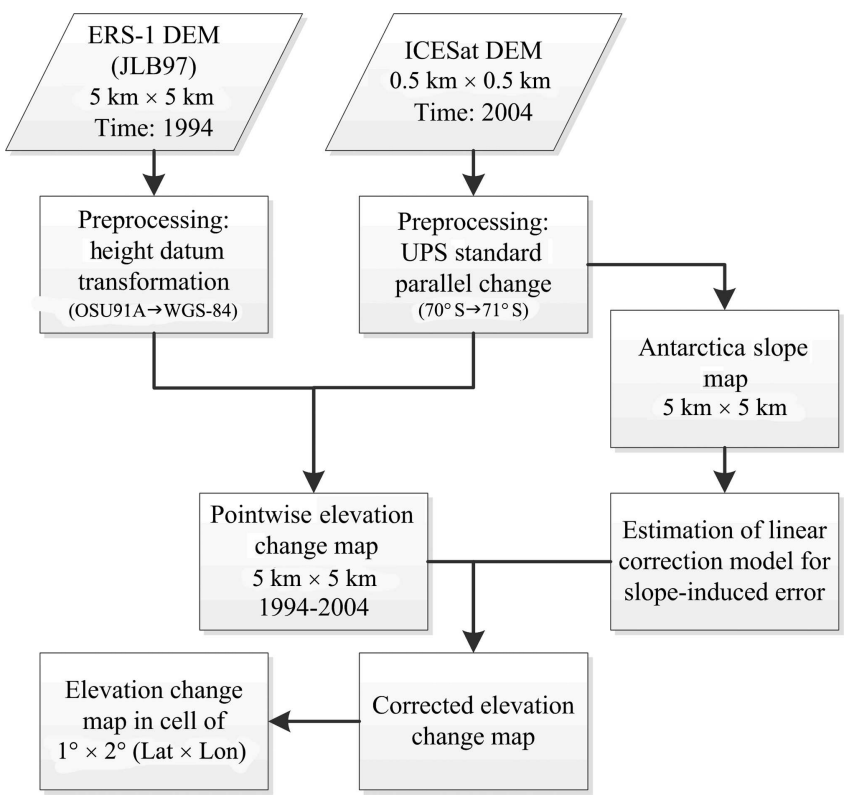

Fig. 1. Flow chart of the adopted procedure for the comparison of the two DEMs.

(Bamber and others, 2009). The resulting DEM had an improved quality because it fused GLAS data featuring higher accuracy but sparser spatial sampling with the ERS-1 observations, which feature denser and more homogeneous spatial sampling but lower vertical accuracy. Unfortunately, this DEM was obtained from data covering a time-span that is too long for the purpose of the analysis of decadal-scale elevation change.

For this reason, here the two original and independent datasets (JLB97 and ICESat DEMs) are reconsidered and compared at grid level. Their potential for decadal-scale icesheet changes was also explored. Some problems caused by the intrinsic limitations of both datasets were expected from the beginning. Looking for solutions to overcome these problems is the purpose of our efforts.

As DEMs of the Antarctic ice-sheet surface from two different periods are available, the elevation change analysis is begun by calculating, in a pointwise manner, the difference $(\mathrm{d} H)$ between the two DEMs for all of the common areas. The overall procedure for processing the DEM comparison is shown in Figure 1.

First, some preliminary data preparation work was afforded for each DEM. This included the transformation of the DEMs into the same geodetic coordinate system. In both cases, elevations with respect to the World Geodetic System 1984 (WGS84) ellipsoid have been used. The standard parallel of the Antarctic Universal Polar Stereographic (UPS) projection for the ICESat DEM has been transformed from $70^{\circ}$, as provided by DiMarzio and others (2007), to $71^{\circ}$ in conformity with that of the JLB97 DEM.

A $5 \mathrm{~km}$ resolution slope map was then created based on the $500 \mathrm{~m}$ resolution ICESat DEM using the third-order finitedifference (3FD) algorithms, a detailed description of which can be found in Zhou and Liu (2004). 3FD is supposed to provide better reliability and more detailed surface information. This slope map is used as a complementary data source for the analysis of errors related to slope.

The next step is calculation of the elevation difference map between the ERS (JLB97) and ICESat DEMs. It is expected that this map will represent the Antarctic surface elevation change distribution for the period 1994-2004 if other errors can be thoroughly corrected. This task required a preliminary resampling of the ICESat DEM at the same resolution as the JLB97 dataset, i.e. $5 \mathrm{~km} \times 5 \mathrm{~km}$. For all gridpoints, a lower resolution for ERS points is used to find the corresponding location in the ICESat DEM where a $15 \times 15$ raster cells neighborhood is defined. The mean in the neighborhood is calculated and compared with the elevation value of the corresponding point in the JLB97 DEM. Finally, potential slope-induced systematic errors are investigated and possible corrections can be introduced for the elevation difference map. More detailed explanation of the applied methodology is given along with the numerical results for an improved clarification.

\section{RESULTS}

The elevation differences from the direct DEM comparison (Fig. 2a) appear to have a dominant trend of negative changes between 1994 and 2004, with some quite large and unreasonable changes (absolute values) larger than $20 \mathrm{~m}$ over 10 years. When performing an assessment of the ERS (JLB97) data accuracy, Bamber and Gomez-Dans (2005) suggested that the mean difference is likely to be no more than $\sim 1.5 \mathrm{~m}$ even in areas of greatest elevation changes based on two ERS RA datasets over 10 years (Wingham and others, 1998; Davis and Ferguson, 2004). Other contributions to these discrepancies may be due to the different abilities of radar versus laser signals in penetrating the snowpack, but these effects should have been at least partially compensated for in both datasets before producing the DEMs. We maintain that residual errors due to this problem should be at a decimeter level.

These considerations suggest that the gridpoints with elevation changes beyond an appropriate threshold should be considered unreasonable and should be examined. A statistical analysis was carried out, in particular, with a dependency analysis of local surface slopes (Fig. 3). Differences of the DEM elevation difference map (dDEM) were grouped into slope bins in the range $\left[0^{\circ}, 2^{\circ}\right]$ at an interval of $0.02^{\circ}$. Mean and standard deviation of the elevation differences were computed for each slope bin. These are plotted in Figure 3. In this way, the presence of some slope-induced trends with the two DEMs is confirmed, as was done by Bamber and Gomez-Dans (2005) when assessing the accuracy of the ERS (JLB97) DEM using ICESat track points. Therefore, a linear trend in the slope range $\left[0^{\circ}, 0.4^{\circ}\right]$ was found and had to be dealt with when comparing the ICESat and ERS (JLB97) DEMs.

According to the near-linear trend in the statistical plot (Fig. 3), the relationship between the mean DEM difference and slope is modeled and used to remove the slope dependency. This is implemented by a first-order polynomial fitting as

$$
\mathrm{d} H=-15.1492 \cdot \text { Slope }-0.28835
$$

where $\mathrm{d} H$ is the elevation difference between the two DEMs and Slope is the associated slope at the gridpoint which comes from the slope map derived from the ICESat data (Fig. 2c). The slope range $\left[0^{\circ}, 0.4^{\circ}\right]$ used to establish the above model is determined by (1) the linear trend observed in Figure 3, and (2) the corresponding upper bound of the standard deviation $(10 \mathrm{~m})$ that makes up $70 \%$ of the entire 

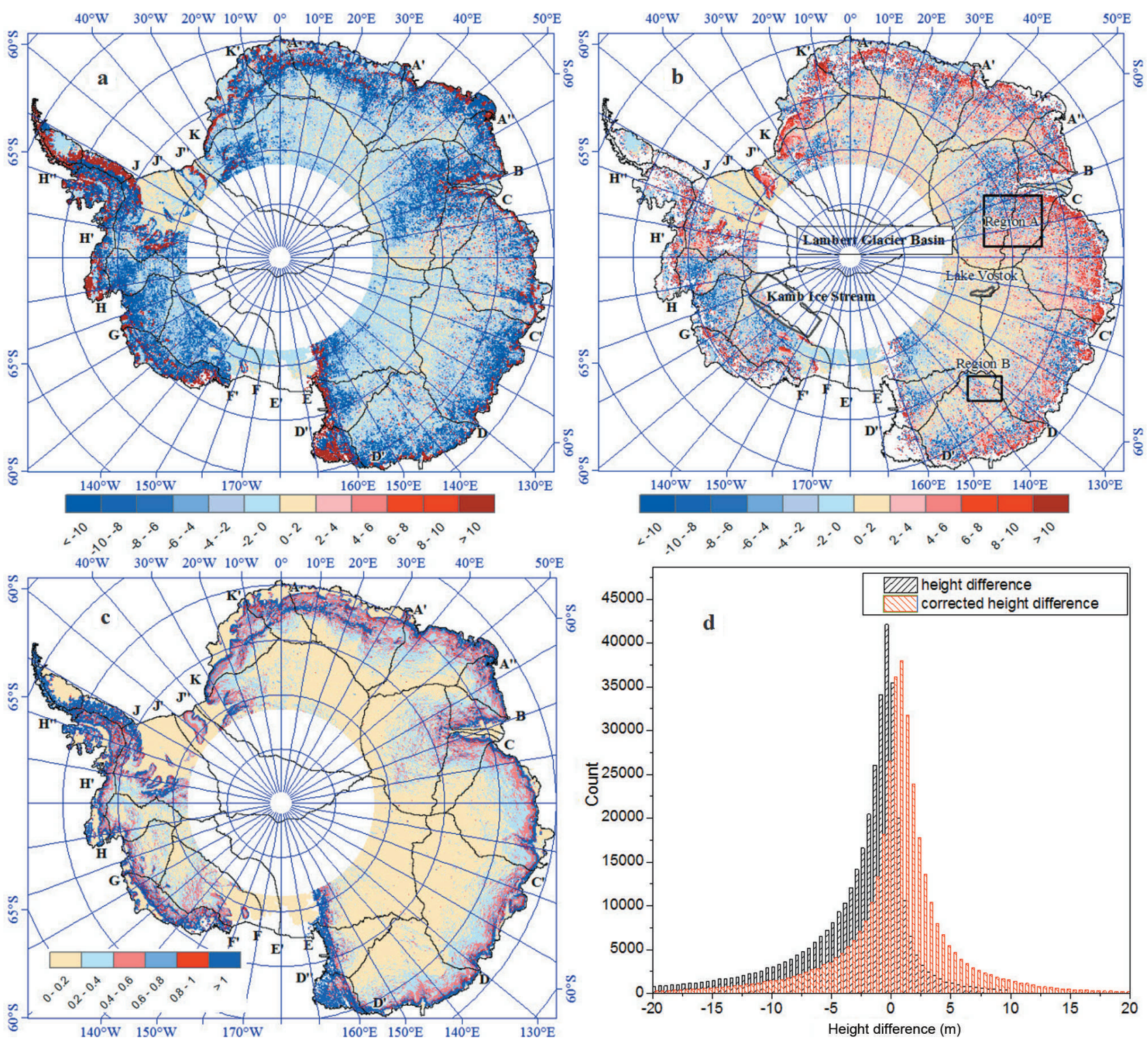

Fig. 2. (a, b) Elevation difference maps obtained from ERS (JLB97) and ICESat DEMs before (a) and after (b) slope-induced error correction (results are shown in meters). (c) The slope map shown in degrees. (d) Histograms of computed differences. Areas of high relief (i.e. surface slope $\left.>2^{\circ}\right)$ and of very large difference $(>20 \mathrm{~m})$ are excluded.

Antarctica area within this slope range. The corrected difference map is shown in Figure $2 b$.

The dominant trend of the overall negative changes in Figure 2a seems to disappear and elevation changes in some of these areas become positive (Fig. 2b). This is confirmed by the shift of the gravity center of the corresponding histograms from $-3.21 \mathrm{~m}$ to $+0.34 \mathrm{~m}$ (Fig. $2 \mathrm{~d}$ ).

As ice shelves are generally flat, the quality of altimetry data can be examined in these regions. For example, except for the calving front, the calculated values of DEM elevation difference on the Ronne-Filchner, Ross (West Antarctica), Larsen (Antarctic Peninsula) and Amery (East Antarctica) ice shelves are generally no more than $1 \mathrm{~m}$ before linear correction and remain almost the same (within $0.1 \mathrm{~m}$ ) after correction (Fig. 2a and b). In addition, the elevation differences in the small portion of the Kamb Ice Stream covered by ERS RA data demonstrate an increase, as expected (Fig. 2b). Furthermore, the Vostok Subglacial Lake area features a relatively minor change between 1994 and 2004, as reported by other publications. Finally, most of the computed differences with high slopes on the Antarctic Peninsula, Transantarctic Mountains and around the coastal areas have been eliminated in the processing chain. DEM

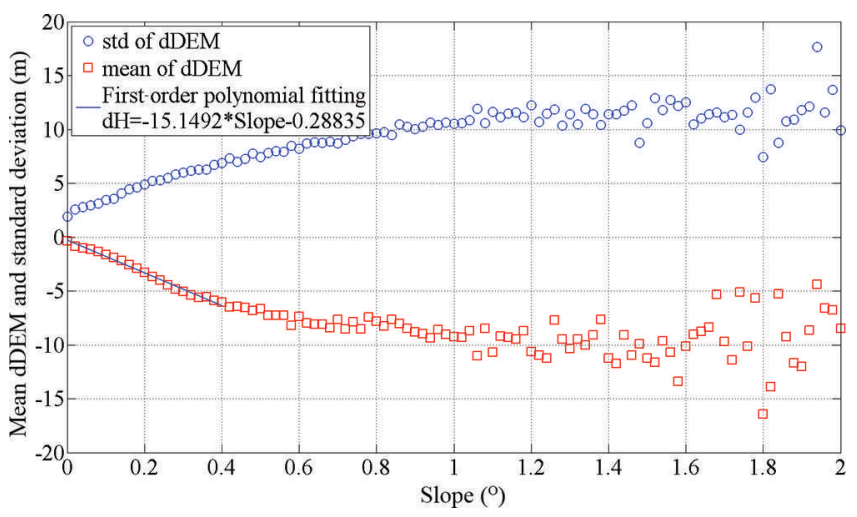

Fig. 3. The statistical relationship between mean, standard deviation and corresponding surface slope. 
Table 2. Elevation changes from 1994 to 2004 and elevation change rate derived from the two DEMs for the Antarctic ice sheet at the drainage basins (Fig. 2b). Corresponding values obtained after reorganizing results from Davis and others (2005) into the basin subdivision recently proposed in Zwally and others (2012) are given for comparison

\begin{tabular}{lrrr}
\hline & \multicolumn{2}{c}{ This study } & Davis and others (2005) \\
Basin & $\mathrm{d} H$ & $\mathrm{~d} H / \mathrm{d} t$ & $\mathrm{~d} H / \mathrm{d} t$ \\
& $\mathrm{~m}$ & $\mathrm{~cm} \mathrm{a}^{-1}$ & $\mathrm{~cm} \mathrm{a}^{-1}$ \\
& & & \\
\hline $\mathrm{E}^{\prime}-\mathrm{F}$ & 0.13 & 1.3 & 3.4 \\
$\mathrm{~F}-\mathrm{F}^{\prime}$ & -1.45 & -15.2 & -2.5 \\
$\mathrm{~F}^{\prime}-\mathrm{G}$ & -0.30 & -3.2 & -2.7 \\
$\mathrm{G}-\mathrm{H}$ & -1.92 & -20.1 & -6.2 \\
$\mathrm{H}-\mathrm{H}^{\prime}$ & 1.33 & 14.0 & 12.1 \\
J-J' & 0.52 & 5.4 & 4.8 \\
$\mathrm{~J}^{\prime}-\mathrm{J}^{\prime \prime}$ & 2.45 & 25.7 & 4.5 \\
West Antarctica $^{\prime}$ & -0.88 & -9.3 & -1.1 \\
$\mathrm{~J}^{\prime \prime}-\mathrm{K}$ & 0.49 & 5.1 & 1.9 \\
$\mathrm{~K}-\mathrm{K}^{\prime}$ & 1.46 & 15.3 & 3.6 \\
$\mathrm{~K}^{\prime}-\mathrm{A}$ & 0.46 & 4.9 & 3.2 \\
$\mathrm{~A}-\mathrm{A}^{\prime}$ & 0.49 & 5.1 & 0.8 \\
$\mathrm{~A}^{\prime}-\mathrm{A}^{\prime \prime}$ & 1.09 & 11.4 & 0.9 \\
$\mathrm{~A}^{\prime \prime}-\mathrm{B}$ & 1.05 & 11.0 & 3.4 \\
$\mathrm{~B}-\mathrm{C}$ & 0.04 & 0.4 & 2.6 \\
$\mathrm{C}-\mathrm{C}^{\prime}$ & 1.71 & 17.9 & 5.7 \\
$\mathrm{C}^{\prime}-\mathrm{D}$ & 0.49 & 5.2 & 1.0 \\
D-D' & -0.14 & -1.4 & 1.0 \\
$\mathrm{D}^{\prime}-\mathrm{D}^{\prime \prime}$ & -0.66 & -7.0 & -1.6 \\
$\mathrm{D}^{\prime \prime}-\mathrm{E}$ & -0.74 & -7.8 & 2.0 \\
E-E' & 0.02 & 0.3 & 1.2 \\
East Antarctica & 0.28 & 3.0 & 2.0 \\
Whole Antarctica $^{\prime}$ & 0.15 & 1.5 & 1.4 \\
& & & \\
\hline & & &
\end{tabular}

elevation differences in the vast interior are between $\sim 2$ and $6 \mathrm{~m}$; this is similar to the conclusions drawn by Griggs and Bamber (2009).

Elevation changes as shown in Figure $2 b$ are further grouped statistically at the Antarctic drainage basin level, separated in the same way as Zwally and others (2012). These are presented in Table 2 after elimination of absolute values greater than $20 \mathrm{~m}$. Corresponding values from Davis and others (2005) are also listed in Table 2, which is based on ERS track point analysis (1992-2003). The elevation changes from that study in 1994-2004 were converted to the elevation change rate $\mathrm{d} H / \mathrm{d} t$ for a more meaningful comparison with the result of Davis and others (2005). Moreover, elevation change rates from both studies were recomputed within the same basin subdivision recently proposed by Zwally and others (2012).

At the ice-sheet scale, $\mathrm{d} H$ values in East Antarctica have an average of $+0.28 \mathrm{~m}$ (change rate of $+3.0 \mathrm{~cm} \mathrm{a}^{-1}$ ) from 1994 to 2004 . Elevation changes $(\mathrm{d} H)$ of single basins range from -0.74 to $+1.71 \mathrm{~m}$ in the same time-span. This demonstrates a general trend of increased surface elevations in East Antarctica. On the other hand, the average $\mathrm{d} H$ value in West Antarctica is $-0.88 \mathrm{~m}$ (change rate of $-9.3 \mathrm{~cm} \mathrm{a}^{-1}$ ), while it ranges from -1.9 to $+2.4 \mathrm{~m}$ for different basins. For the whole of Antarctica, the average $\mathrm{d} H$ result was $+0.15 \mathrm{~m}$, corresponding to an elevation change rate of $+1.5 \mathrm{~cm} \mathrm{a}^{-1}$. This outcome is in good agreement with Davis and others (2005), who obtained a rate of $+1.4 \mathrm{~cm} \mathrm{a}^{-1}$. When elevation change rates in East and West Antarctica are compared, however, results show a lower level of similarity, especially in the western subcontinent.

At the basin scale, it can be seen that in most basins $(70 \%)$ the elevation change rates of this study are comparable (discrepancy $<10 \mathrm{~cm} \mathrm{a}^{-1}$ ) to those found by Davis and others (2005). For $55 \%$ and $25 \%$ of basins, departures between the elevation change rates computed in both studies are below 5 and $2 \mathrm{~cm} \mathrm{a}^{-1}$, respectively. This level of difference seems to be acceptable considering the different time-spans, i.e. 1994-2004 in this study vs 1992-2003 in Davis and others (2005). For 18 basins out of a total of 20, the sign of $\mathrm{d} H / \mathrm{d} t$ was the same in both analyses. The exceptions are basins D-D' (George $V$ Land) and $D^{\prime \prime}-E$ (Victoria Land). In the former case, computed elevation change rates showed only a small difference $\left(-1.4 \mathrm{~cm} \mathrm{a}^{-1} \mathrm{vs}\right.$ $\left.+1.0 \mathrm{~cm} \mathrm{a}^{-1}\right)$. In the latter, discrepancy between the two results was larger $\left(-7.8 \mathrm{~cm} \mathrm{a}^{-1} \mathrm{vs}+2.0 \mathrm{~cm} \mathrm{a}^{-1}\right)$, but this basin is characterized by the presence of high reliefs on the coast that may have lessened the quality of the RA data. This means that by comparing DEMs it was possible to find the trend direction. However, the magnitude of change rates is generally overestimated (Table 2). In West Antarctica, three basins whose territory mostly extended over coastal regions showed larger changes than in Davis and others (2005): basins F-F' (Marie Byrd Land) and G-H (Thwaites Glacier and inland) confirmed a thinning trend, while basin $\mathrm{J}^{\prime}-\mathrm{J}^{\prime \prime}$ (around Berkner Island) resulted in thickening. In the case of Thwaites Glacier, the results $\left(-20.1 \mathrm{~cm} \mathrm{a}^{-1}\right)$ are more in agreement with Flament and Rémy (2012), who found an elevation change rate of $-18 \mathrm{~cm} \mathrm{a}^{-1}$ during 2002-10 from analysis of Envisat RA. In East Antarctica, basins with larger departures in both studies also spread out over coastal regions $\left(K-K^{\prime}\right.$ around Brunt Ice-Shelf, $A^{\prime}-A^{\prime \prime}$ in Dronning Maud Land, $A^{\prime \prime}-B$ in Kemp Land, and $C-C^{\prime}$ from Princess Elizabeth to Queen Mary Land), sometimes including steep relief areas such as $\mathrm{D}^{\prime}-\mathrm{D}^{\prime \prime}$ (Oates Land).

Discrepancies can be motivated by different reasons. The largest differences were found in coastal areas, where RA data suffer most because of the steep slopes. In the present dataset, RA and LA were integrated, while Davis and others (2005) used homogeneous ERS data only. A similar consideration can be made for the typology of the dataset compared, i.e. grid DEMs obtained from sparse data interpolation vs track crossovers. Different slope-induced error corrections may have been applied, as well as different criteria for filtering out points used for computing elevation changes. A minor contribution might also come from actual ice surface changes during the period not shared by the two datasets, as well as other secondary reasons.

Changes at the $5 \mathrm{~km} \times 5 \mathrm{~km}$ gridpoints in Figure $2 \mathrm{~b}$ show some weaknesses. First, in much of the interior part of East Antarctica, patterns of ICESat tracks are apparent. Figure 4 shows an enlarged region marked ' $\mathrm{B}$ ' in Figure $2 \mathrm{~b}$, where ICESat tracks are overlaid on the elevation difference map. It can be seen that extreme $\mathrm{d} H$ values (larger than $20 \mathrm{~m}$, or less than $-20 \mathrm{~m}$ ) exist in areas enclosed by ascending and descending tracks. This may be attributed to interpolation errors of gridpoints between ICESat tracks when computing the corresponding DEM (see discussion in Bamber and others, 2009).

Second, there is a significant level of high-frequency noise, as can be seen in the examples reported in Figures 5 and 6 (regions $\mathrm{A} 1$ and $\mathrm{A} 2$ ). For instance, in the inner region of the Lambert Glacier basin, gridpoints with high positive 


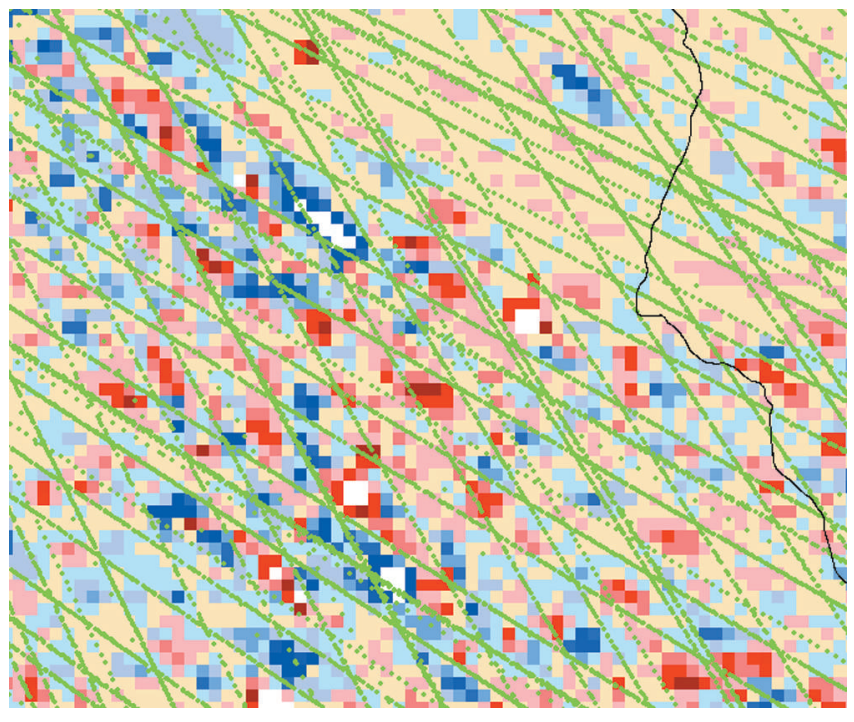

Fig. 4. Overlay of ICESat tracks onto the $\mathrm{d} H$ map and potential interpolation errors of gridpoints between tracks in region $\mathrm{B}$ in Figure $2 b$.

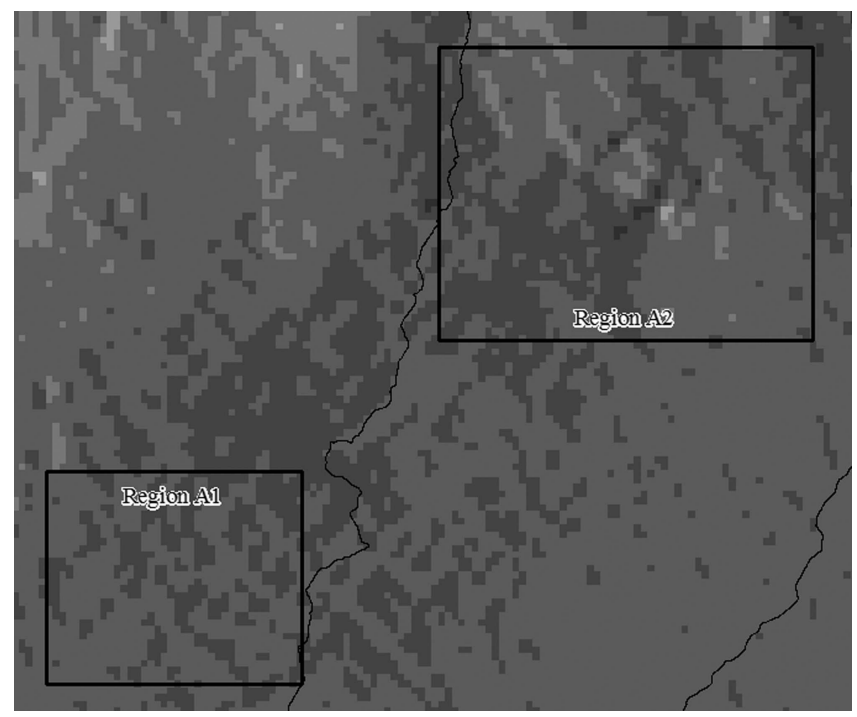

Fig. 5. Enlarged shade relief map of the ERS DEM showing region A in Figure $2 \mathrm{~b}$ (point-of-view at azimuth $90^{\circ}$ and elevation $15^{\circ}$ ). elevation change are sometimes immediately adjacent to areas featuring higher slopes in the ERS DEM. A further examination of the datasets in Figure 6 demonstrated that such high-frequency noise comes from the ERS DEM.

The above-mentioned weaknesses may restrict the application of these two DEM products, which require detection of elevation changes at the gridpoint level.

\section{DISCUSSION AND CONCLUSIONS}

The results of an experimental attempt to compare two publicly available DEM mapping products of Antarctica derived from ERS and ICESat altimetry data sources have been presented. Both DEMs were independently obtained from interpolation of data after filtering and preprocessing to correct main errors related to the data acquisition processes. As noted in the literature (Bamber and others, 2009), the radar altimetry ERS-1 DEM (JLB97) features lower elevation accuracy but denser spatial sampling, while the laser altimetry ICESat DEM has complementary properties. Moreover, the JLB97 covers the whole of Antarctica, though in several regions the lack of radar data was filled in with information from previous maps, whose quality may not be adequate for elevation change analysis. This is particularly evident in highslope regions $\left(>2^{\circ}\right)$. The basic concept of this work is based on analysis of these two DEMs to compute elevation changes after a series of systematic data-processing steps.

Overall, we found that the two DEM products inherited their advantages from radar and laser altimetry and provided topographic data describing the surface elevations of the ice sheet at the times of data acquisition. They can be used to represent the Antarctic surface at resolutions of $5 \mathrm{~km}$ (ERS-1/ JLB97) and $500 \mathrm{~m}$ (ICESat) for visualization and other similar purposes. The elevation changes derived from the two DEMs can be employed to produce aggregated surface changes at ice-sheet scales, as demonstrated by the comparison of results obtained here with those reported from previous studies (Davis and others, 2005). The use of a DEM becomes more critical when looking at smaller regions. At the drainage basin level, for example, some problems have been found, especially in the coastal areas. While the direction of the elevation change trend has confirmed the results from previous literature in 18 basins out of 20, in many cases larger variations have been found.
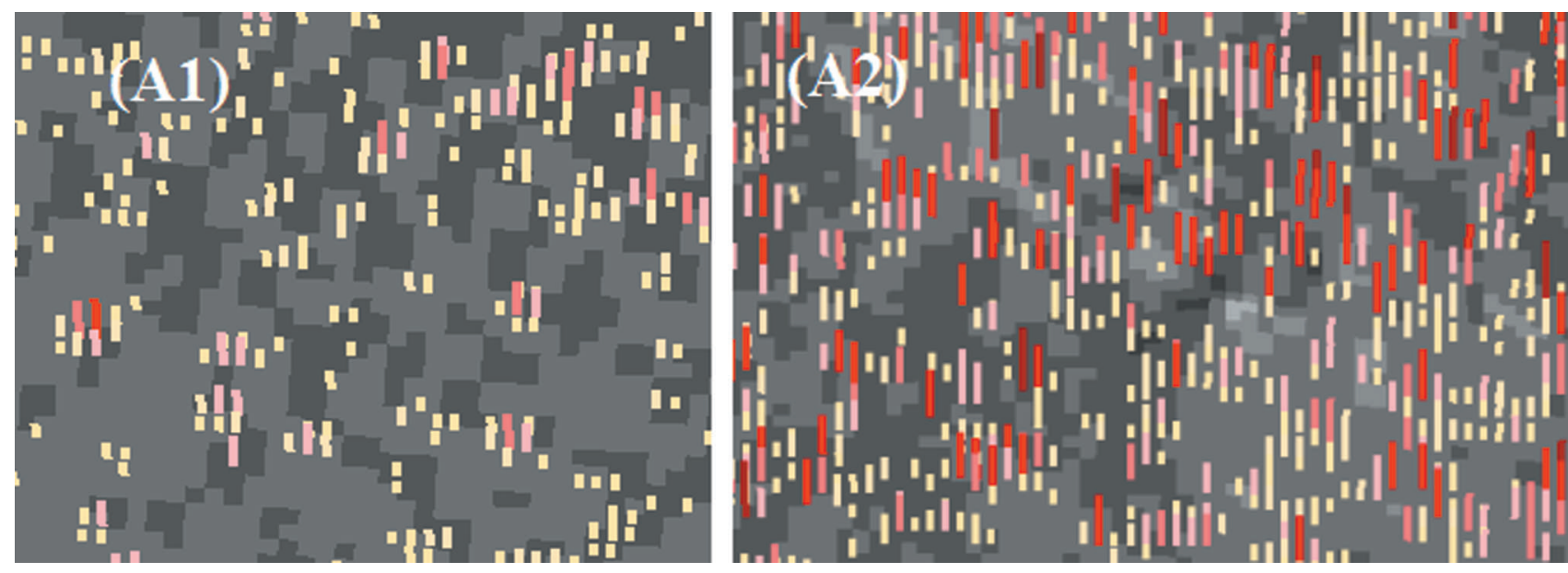

Fig. 6. Zoom-in of regions $\mathrm{A} 1$ and $\mathrm{A} 2$ in Figure 5, where $\mathrm{d} H$ are overlapped over shaded relief maps. Red bars represent elevation increases and in most cases are close to darker cells of shaded relief maps of the ERS DEM. For clarity, decreases in $\mathrm{d} H$ are not shown here. 
Detection of elevation changes at the resolution of the original DEMs $(5 \mathrm{~km}$ and $500 \mathrm{~m})$ is a major challenge because of a number of factors. One factor is associated with interpolation errors for the points between altimetry tracks (particularly for ICESat). Another is related to the inaccuracy of gridpoints in high-slope areas where elevation errors often exceed reasonable expected ranges. Moreover, in some gently sloped areas there exists high-frequency noise in derived elevation differences attributed to the ERS-1 DEM that sets significantly high and low elevations immediately adjacent to each other.

Future work will address how to derive altimetry information from the latest generation of radar satellite altimetry missions (e.g. CryoSat-2), which may provide better spatial and temporal resolution. Further factors influencing the quality of the DEM (e.g. surface roughness) also deserve investigation. Considering the problems encountered with ICESat DEMs due to uneven spatial interpolation, future analysis will be based on original laser tracks rather than on DEMs. Contemporaneously, computed volumes will be exploited to derive ice-mass balance, this being the final aim of this research.

\section{ACKNOWLEDGEMENTS}

This study is supported by the National Key Basic Research Program of China (973 Program, project No. 2012CB957701, 2012CB719903), the National High Technology Research and Development Program of China (863 Program, project No. 2012AA12A305), the National Science Foundation of China (project No. 41171327, 41201379), the Specialized Research Fund for the Doctoral Program of Higher Education (project No. 20120072120057), and the Open Research Fund of the State Key Laboratory of Information Engineering in Surveying, Mapping and Remote Sensing (project No. 12E02). We also thank the US National Snow and Ice Data Center and the European Space Agency for providing the ICESat and JLB97 DEM datasets, respectively.

\section{REFERENCES}

Bamber JL (1994) Ice sheet altimeter processing scheme. Int. J. Remote Sens., 15(4), 925-938 (doi: 10.1080/ 01431169408954125)

Bamber JL (2000) Antarctic 5-km digital elevation model from ERS1 altimetry. National Snow and Ice Data Center, Boulder, CO

Bamber JL and Bindschadler RA (1997) An improved elevation dataset for climate and ice-sheet modelling: validation with satellite imagery. Ann. Glaciol., 25, 439-444

Bamber J and Gomez-Dans JL (2005) The accuracy of digital elevation models of the Antarctic continent. Earth Planet. Sci. Lett., 237(3-4), 516-523 (doi: 10.1016/j.epsl.2005.06.008)
Bamber JL, Gomez-Dans JL and Griggs JA (2009) A new $1 \mathrm{~km}$ digital elevation model of the Antarctic derived from combined satellite radar and laser data - Part 1: data and methods. Cryosphere, 3(1), 101-111 (doi: 10.5194/tc-3-101-2009)

Davis $\mathrm{CH}$ and Ferguson AC (2004) Elevation change of the Antarctic ice sheet, 1995-2000, from ERS-2 satellite radar altimetry. IEEE Trans. Geosci. Remote Sens., 42(11), 2437-2445 (doi: 10.1109/TGRS.2004.836789)

Davis CH, Li Y, McConnell JR, Frey MM and Hanna E (2005) Snowfall-driven growth in East Antarctic ice sheet mitigates recent sea-level rise. Science, 308(5730), 1898-1901 (doi: 10.1126/science.1110662)

DiMarzio JP, Brenner A, Fricker H, Schutz R, Shuman CA and Zwally HJ (2007) GLAS/ICESat $500 \mathrm{~m}$ laser altimetry digital elevation model of Antarctica. National Snow and Ice Data Center, Boulder, CO

Flament T and Rémy F (2012) Dynamic thinning of Antarctic glaciers from along-track repeat radar altimetry. J. Glaciol., 58(211), 830-840 (doi: 10.3189/2012JoG11J118)

Griggs JA and Bamber JL (2009) A new 1 km digital elevation model of Antarctica derived from combined radar and laser data - Part 2: validation and error estimates. Cryosphere, 3(1), 113-123 (doi: 10.5194/tc-3-113-2009)

Gunter B and 8 others (2009) A comparison of coincident GRACE and ICESat data over Antarctica. J. Geod., 83(11), 1051-1060 (doi: 10.1007/s00190-009-0323-4)

Hurkmans RTWL, Bamber JL and Griggs JA (2012) Brief communication. 'Importance of slope-induced error correction in volume change estimates from radar altimetry'. Cryosphere, 6(2), 447-451 (doi: 10.5194/tc-6-447-2012)

Rémy F, Flament T, Blarel F and Benveniste J (2012) Radar altimetry measurements over antarctic ice sheet: a focus on antenna polarization and change in backscatter problems. Adv. Space Res., 50(8), 998-1006 (doi: 10.1016/j.asr.2012.04.003)

Rignot E and Thomas RH (2002) Mass balance of polar ice sheets. Science, 297(5586), 1502-1506 (doi: 10.1126/science. 1073888)

Shepherd A and 46 others (2012) A reconciled estimate of ice-sheet mass balance. Science, 338(6111), 1183-1189 (doi: 10.1126/ science.1228102)

Wingham DJ, Ridout AL, Scharroo R, Arthern RJ and Shum CK (1998) Antarctic elevation change from 1992 to 1996. Science, 282(5388), 456-458 (doi: 10.1126/science.282.5388.456)

Wingham DJ and 15 others (2006a) CryoSat: a mission to determine the fluctuations in Earth's land and marine ice fields. Adv. Space Res., 37(4), 841-871 (doi: 10.1016/ j.asr.2005.07.027)

Wingham DJ, Shepherd A, Muir A and Marshall GJ (2006b) Mass balance of the Antarctic ice sheet. Philos. Trans. R. Soc. London, Ser. A, 364(1844), 1627-1635 (doi: 10.1098/rsta.2006.1792)

Zhou Q and Liu X (2004) Analysis of errors of derived slope and aspect related to DEM data properties. Comput. Geosci., 30(4), 369-378 (doi: 10.1016/j.cageo.2003.07.005)

Zwally HJ, Giovinetto MB, Beckley MA and Saba JL (2012) Antarctic and Greenland drainage systems. GSF Cryospheric Sciences Laboratory, Greenbelt, MD (http://icesat4.gsfc.nasa. gov/cryo_data/ant_grn_drainage_systems.php) 